\title{
QUANTITATIVE STUDIES OF NASAL CARRIERS OF STAPHYLOCOCCI AMONG HOSPITAI.IZED PATIENTS*
}

\author{
BY ARTHUR WHITE $\dagger$ \\ (From the Department of Medicine, University of Louisville School of Medicine Louisville, Ky.)
}

(Submitted for publication March 9, 1960; accepted September 8, 1960)

Several investigators have shown that patients who are nasal carriers of staphylococci have a higher incidence of postoperative infections and other types of staphylococcal disease than have patients who are not nasal carriers $(1,2)$. In these studies, the increased incidence of infections was due predominantly to staphylococci of the same phage type as those isolated from the nose of the patient before the infections occurred.

If the nasal carrier is a major source of his own hospital-acquired staphylococcal infection, qualitative and quantitative changes in the nasal flora of staphylococci should be important in understanding the origin of a portion of staphylococcal disease. Several reports have been made of qualitative studies of nasal carriers of staphylococci in hospitalized patients (3-6). Williams and colleagues (1) found that carriers of tetracyclineresistant strains had a higher incidence of infections than had carriers of tetracycline-sensitive strains. Also carriers of "virulent" strains, which were defined as staphylococci causing two or more infections in a short period, had more frequent infections than carriers of "nonvirulent" strains.

Quantitative studies of nasal carriers have been reported from a mental hospital having a reservoir of largely drug-susceptible staphylococci (7, 8). Similar studies have been continued in a general hospital with a large proportion of physically ill patients and a large reservoir of antibiotic-resistant staphylococci. In this setting, the dissemination of staphylococci to a patient's environment was correlated with the quantity of staphylococci that could be recovered from his nose. In addition, carriers of $80 / 81$ staphylococci and patients with certain diseases were found to be heavier

* This study was supported by Grant E-2561 from the National Institute of Allergy and Infectious Diseases, Bethesda, Md.

$\dagger$ John and Mary R. Markle Scholar in Medical Science. nasal carriers and therefore potentially greater disseminators of staphylococci than were patients without these characteristics.

\section{MATERIALS AND METHODS OF STUDY}

Nasal cultures were made 3 to 5 times per week on all patients on a male medical ward, a female medical ward or a male surgical ward at the Louisville General Hospital in the period from October 1958 to August 1959.

During this period sweep plates were made of the patients' clothing by sweeping open $100 \times 15 \mathrm{~mm}$ petri dishes with Tryptic Soy Agar (Difco) over the anterior surface of the patients' gowns from shoulder to groin three times on each side.

The laboratory procedures employed have been described in detail previously (7) but some of the pertinent procedures are summarized below.

Both sides of the nose were swabbed with sterile cotton applicators moistened in broth. The swabs were shaken in a measured volume of broth, and coagulasepositive pigmented colonies were enumerated in appropriate dilutions. In the present report the term staphylococci is restricted to coagulase-positive micrococcus pyogenes var. aureus.

Phage typing was performed using the following 22 phages: group I, 29, 52, 52a, 79, 80 ; group II, 3a, 3b, 3c, 55.71 ; group III, $6,7,42 \mathrm{e}, 47,53,54,73,75,77, \mathrm{Va}_{4}$; and unclassified, $81,42 \mathrm{~b}$.

Phages were propagated in heart infusion broth with 0.004 mole per $\mathrm{L}$ of added $\mathrm{CaCl}_{2}$ (9). The staphylococci were first tested with the lowest concentration of phage which lysed the propagating strain and, if fewer than 20 plaques were present with all phages, they were then retested with a 1,000-fold higher concentration. Staphylococci which reacted with more than one phage were classified according to the predominant reactions.

Drug susceptibility tests were performed by inoculating the surface of an agar plate into which specified concentrations of various antibiotics were incorporated with an overnight culture of the strain to be tested. Staphylococci were considered susceptible to penicillin if they were inhibited by $1.6 \mu \mathrm{g}$ per $\mathrm{ml}$ and to tetracycline, chloramphenicol, erythromycin, kanamycin, novobiocin or furaltadone if inhibited by $6.2 \mu \mathrm{g}$ per $\mathrm{ml}$ of these drugs. Organisms not inhibited by these concentrations were considered to be resistant. 
TABLE I

Susceptibility of slaphylococci from hospital-acquired lesions or from nasal carriers to penicillin, tetracycline, erythromycin and chloramphenicol

\begin{tabular}{|c|c|c|}
\hline Resistant to: & $\begin{array}{l}\text { Lesions, } \\
100 \text { strains }\end{array}$ & $\begin{array}{c}\text { Carriers, } \\
2,134 \text { strains }\end{array}$ \\
\hline & $\%$ & $\%$ \\
\hline None of the 4 drugs & 9.0 & 24.6 \\
\hline Pen. only & 10.0 & 21.1 \\
\hline Pen. and tetra. & 29.07 & $18.1)$ \\
\hline $\begin{array}{l}\text { Pen., tetra. and } \\
\text { erythro. }\end{array}$ & 10.0 & 8.0 \\
\hline $\begin{array}{l}\text { Pen., tetra. and } \\
\text { chlor. }\end{array}$ & $8.0\}^{79.0^{*}}$ & $5.1\} 44.6^{*}$ \\
\hline $\begin{array}{l}\text { Pen., tetra., chlor. } \\
\text { and erythro. }\end{array}$ & 32.0 & 13.4 \\
\hline $\begin{array}{l}\text { Other resistance } \\
\text { patterns }\end{array}$ & 2.0 & 9.7 \\
\hline Total & 100.0 & 100.0 \\
\hline
\end{tabular}

* Strains from lesions were more frequently resistant to both penicillin and tetracycline than were strains from carriers $\left(\chi^{2}: \mathrm{p}<0.01\right)$.

\section{RESULTS}

Drug susceptibility of staphylococci from hospital-acquired lesions and from nasal carriers. In Table I are shown the major resistance patterns of 100 strains of staphylococci isolated from hospital-acquired lesions and of 2,134 strains isolated from nasal carriers.

Fifty-four of the strains from lesions were iso-
TABLE II

Phage pallerns of shaphylococci from hospilal-acquired lesions or from hospitalized nasal carriers

\begin{tabular}{lcc}
\hline Phage reactions & $\begin{array}{c}\text { Lesions, } \\
\text { 100 strains }\end{array}$ & $\begin{array}{c}\text { Carriers, } \\
\text { 2,134 strains }\end{array}$ \\
\hline & $\%$ & $\%$ \\
Group I & 4.0 & 2.3 \\
Group II & 11.0 & 7.6 \\
Group III & 8.0 & 30.4 \\
Not typeable & 13.0 & 23.1 \\
Misc. & 0.0 & 10.5 \\
80/81 & $64.0^{*}$ & $26.1^{*}$ \\
Total & 100.0 & 100.0
\end{tabular}

* More strains from lesions than strains from carriers were lysed by phages $80 / 81\left(\chi^{2}: p<0.01\right)$.

lated from patients who had received antimicrobial drugs before the onset of staphylococcal infections. In 31 patients, antibiotics were administered to prevent postoperative or other infections and in 23 patients, for the treatment of other bacterial diseases including pneumococcal pneumonia, pyelonephritis and bacteremias. Thirty-four patients received penicillin with or without streptomycin, 10 received chloramphenicol, 2 tetracycline, 4 penicillin and erythromycin, and 4 patients received both penicillin and chloramphenicol.

Staphylococci isolated from lesions were more frequently resistant to each of the four drugs and to both penicillin and tetracycline than were

TABLE III

Antimicrobial resistance of staphylococci of various phage groups

\begin{tabular}{|c|c|c|c|c|c|c|}
\hline \multirow[b]{2}{*}{ Phage group } & \multicolumn{6}{|c|}{ Resistant to: } \\
\hline & $\begin{array}{l}\text { Pen. } \\
\text { only }\end{array}$ & $\begin{array}{l}\text { Pen., } \\
\text { tetra. }\end{array}$ & $\begin{array}{l}\text { Pen., } \\
\text { tetra., } \\
\text { eryth. }\end{array}$ & $\begin{array}{l}\text { Pen., } \\
\text { tetra., } \\
\text { chlor. }\end{array}$ & $\begin{array}{l}\text { Pen., } \\
\text { tetra., } \\
\text { chlor., } \\
\text { eryth. }\end{array}$ & $\begin{array}{c}\text { Total } \\
\text { multiple } \\
\text { resistance }\end{array}$ \\
\hline $\begin{array}{l}\text { Group I } \\
50 \text { strains }\end{array}$ & $\begin{array}{c}\% \\
24.0\end{array}$ & $\begin{array}{l}\% \\
0.0\end{array}$ & $\begin{array}{l}\% \\
6.0\end{array}$ & $\begin{array}{l}\% \\
0.0\end{array}$ & $\begin{array}{l}\% \\
4.0\end{array}$ & $\begin{array}{r}\% \\
10.0\end{array}$ \\
\hline $\begin{array}{l}\text { Group II } \\
160 \text { strains }\end{array}$ & 34.4 & 3.1 & 0.0 & 1.3 & 1.3 & 5.7 \\
\hline $\begin{array}{r}\text { Not typeable } \\
493 \text { strains }\end{array}$ & 16.9 & 7.1 & 6.3 & 6.7 & 13.8 & 34.9 \\
\hline $\begin{array}{l}\text { Misc. } \\
225 \text { strains }\end{array}$ & 43.5 & 12.4 & 4.4 & 2.7 & 2.2 & 21.7 \\
\hline $\begin{array}{l}\text { Group III } \\
649 \text { strains }\end{array}$ & 26.4 & 13.6 & 13.2 & 4.3 & 12.6 & $43.7^{*}$ \\
\hline $\begin{array}{l}80 / 81 \\
557 \text { strains }\end{array}$ & 5.2 & 41.3 & 7.2 & 7.0 & 22.8 & $78.3^{*}$ \\
\hline
\end{tabular}

* Strains lysed by phages $80 / 81$ were more frequently multiple drug-resistant than were strains lysed by phages of group III $\left(x^{2}: p<0.01\right)$. 
staphylococci isolated from carriers. In both groups, staphylococci resistant to the more recently introduced antibiotics tended also to be resistant to the older drugs; thus, 95.2 per cent of staphylococci resistant to tetracycline were also resistant to penicillin, 97.0 per cent of staphylococci resistant to erythromycin were resistant to both penicillin and tetracycline, and 74.3 per cent of staphylococci resistant to chloramphenicol were also resistant to both penicillin and tetracycline. Novobiocin, kanamycin and furaltadone (Altafur) have been used infrequently in this hospital and less than 1 per cent of staphylococci was resistant to any of the three drugs.

Phage types of staphylococci from hospital-acquired lesions and from nasal carriers. When the staphylococci from lesions and carriers were phage-typed it was found that 64 per cent of the staphylococci from lesions were susceptible to phages 80 and/or 81 , but only 26 per cent of staphylococci from carriers were lysed by these phages (Table II). Thirty per cent of strains from carriers were lysed by phages belonging to group III, but group III staphylococci were responsible for only 8 per cent of hospital-acquired lesions.

Drug susceptibility of staphylococci of various phage groups. There was a marked difference in the frequency with which staphylococci of various phage groups were multiple drug-resistant. Seventy-eight per cent of phage type 80/81 staphylococci was resistant to both penicillin and tetracycline and 37 per cent was resistant to both of these drugs and to erythromycin or chloramphenicol or both (Table III). Forty-four per cent of

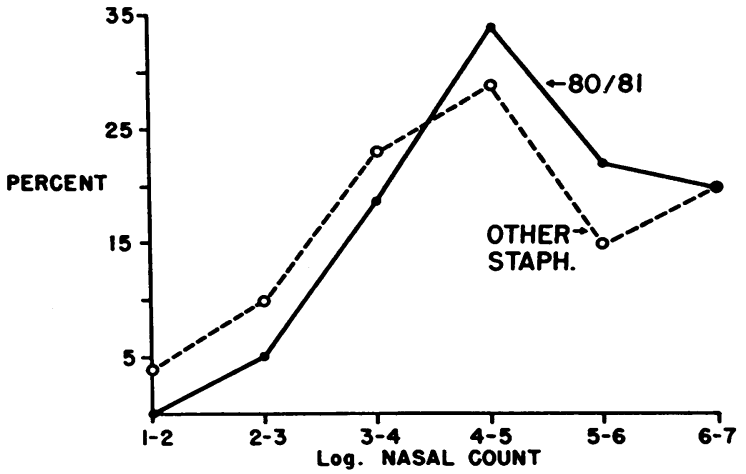

Fig. 1. Cultures from untreated Carriers of the 80/81 STRAIN CONTAINED 10,000 OR MORE COLONIES PER SWAB MORE FREQUENTLY THAN DID CULTURES FROM UNTREATED CARRIERS OF OTHER TYPES OF STAPHYLOCOCCI.

phage group III staphylococci were resistant to both penicillin and tetraycline and 30 per cent were resistant to both of these drugs and also to erythromycin or chloramphenicol or both. A much smaller proportion of staphylococci in other phage groups was multiple drug-resistant.

Correlation of phage types and quantitative nasal cultures. Quantitative nasal cultures were obtained from 175 patients without overt staphylococcal infections who did not receive systemic antibiotics before the cultures were taken. Seventy-seven per cent of 82 cultures from carriers of $80 / 81$ staphylococci contained more than $10^{4}$ colonies per swab, but only 64 per cent of 420 cultures from carriers of other types of staphylococci contained this many colonies (Figure 1).

Correlations between carrier rates and quantitative counts. When at least five consecutive nasal cultures were made from 106 patients who

TABLE IV

Quantitative nasal cultures in untreated patients with different carrier rates

\begin{tabular}{|c|c|c|c|c|c|c|c|}
\hline \multirow[b]{2}{*}{$\begin{array}{c}\text { Carrier } \\
\text { rate }\end{array}$} & \multirow[b]{2}{*}{ Patients } & \multirow[b]{2}{*}{ Cultures } & \multirow{2}{*}{$\begin{array}{l}\text { Positive } \\
\text { cultures }\end{array}$} & \multicolumn{4}{|c|}{ Quantitative counts of positive cultures } \\
\hline & & & & $>10^{3}$ & $>10^{4}$ & $>10^{5}$ & $>10^{6}$ \\
\hline & No. & No. & No. & $\%$ & $\%$ & $\%$ & $\%$ \\
\hline 0 & 41 & 348 & 0 & & & & \\
\hline $1-20$ & 15 & 168 & 21 & 79.2 & $31.6^{*}$ & 5.3 & 5.3 \\
\hline $20-40$ & 5 & 82 & 18 & 88.9 & 61.1 & 16.7 & 0.0 \\
\hline $40-60$ & 11 & 144 & 70 & 82.3 & 63.2 & 22.0 & 10.3 \\
\hline $60-80$ & 6 & 63 & 44 & 90.9 & 75.0 & 38.6 & 15.9 \\
\hline $80-100$ & 28 & 3.3 .3 & 292 & 89.6 & $73.6^{*}$ & 47.2 & 27.2 \\
\hline Total & 106 & 1,138 & 445 & & & & \\
\hline
\end{tabular}

* Patients with carrier rates of 80 to 100 per cent had a larger proportion of positive cultures with more than $10^{4}$ colonies per swab than had patients with carrier rates of 1 to 20 per cent $\left(x^{2}: p<0.01\right)$. 
did not receive antimicrobial drugs, staphylococci were isolated from 28 patients in at least 80 per cent of the cultures. No staphylococci were isolated from any of the cultures from 41 patients, and in the remaining 37 patients, the carrier rates ranged from 0 to 80 per cent.

Only 5.3 per cent of the positive cultures from patients with carrier rates between 1 and 20 per cent contained more than $10^{5}$ colonies per swab. In cultures from patients with higher carrier rates, the proportion of positive cultures containing more than $10^{5}$ per swab progressively increased so that 47.2 per cent of positive cultures from patients with carrier rates of 80 to 100 per cent contained at least this number (Table IV). Similarly, 31.6 per cent of positive cultures from patients with carrier rates of 1 to 20 per cent, and 73.6 per cent of positive cultures from patients with carrier rates greater than 80 per cent, contained more than $10^{4}$ colonies per swab. Thus, patients with the highest carrier rates also tended to have the greatest number of staphylococci in the positive cultures.

Relationship between quantitative counts and dissemination of staphylococci. An attempt was made to correlate nasal counts with dissemination of staphylococci by making quantitative nasal counts and sweep plates of the clothing of patients without staphylococcal infections, approximately 4 hours after their bedclothes had been changed. Staphylococci were isolated from 43 per cent of 80 sweep plates from patients with nasal counts greater than $10^{4}$ colonies per swab, but from only 24 per cent of 37 plates from patients with counts less than $10^{4}$ colonies per swab (Figure 2). Staphylococci isolated from plates were the same phage type as staphylococci in the patient's nose

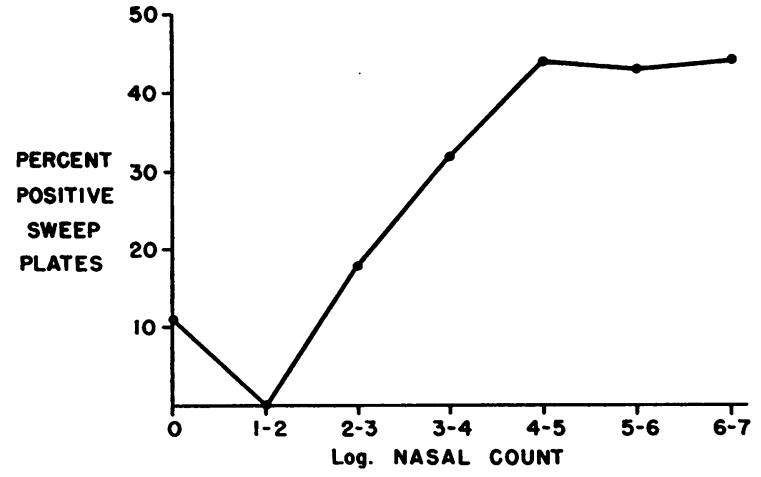

Fig. 2. SWeEp plates of Patients' Clothing CONTAINED COAGULASE-POSITIVE STAPHYLOCOCCI IN OVER 40 PER CENT OF SAMPLES FROM CARRIERS OF 10,000 OR MORE STAPHYLOCOCCI PER SWAB. Coagulase-positive staphylococci were isolated less frequently from the clothing of noncarriers or carriers of fewer than 10,000 colonies per swab.

in all but 6 of 44 positive sweep plates from carriers. In the remaining 6 patients and in the 20 positive sweep plates from noncarriers, staphylococci were presumably obtained from sources other than the nose of the patient.

The effect of antimicrobial drugs on nasal cultures. There was no significant difference in the carrier rates of patients receiving penicillin, as compared with patients who did not receive antimicrobial drugs (Table $\mathrm{V}$ ). In patients receiving erythromycin, to which only 21 per cent of all strains from carriers were resistant, the carrier rate fell from 44 per cent during the first three days of treatment to 18 per cent in patients who received erythromycin for longer than 9 days. The carrier rate was higher in patients treated with tetracycline than in untreated patients in all periods of treatment.

TABLE V

Carrier rates in patients receiving antimicrobial drugs

\begin{tabular}{|c|c|c|c|c|c|c|c|c|}
\hline \multirow[b]{2}{*}{$\begin{array}{l}\text { Treatment } \\
\text { No. of days }\end{array}$} & \multicolumn{2}{|c|}{$\begin{array}{l}\text { Penicillin, } \\
76 \text { patients }\end{array}$} & \multicolumn{2}{|c|}{$\begin{array}{l}\text { Tetracycline, } \\
23 \text { patients }\end{array}$} & \multicolumn{2}{|c|}{$\begin{array}{l}\text { Erythromycin, } \\
\mathbf{4 1} \text { patients } \\
\end{array}$} & \multicolumn{2}{|c|}{$\begin{array}{c}\text { No treatment, } \\
271 \text { patients } \\
\end{array}$} \\
\hline & Cultures & $\begin{array}{c}\text { Carrier } \\
\text { rate }\end{array}$ & Cultures & $\begin{array}{l}\text { Carrier } \\
\text { rate }\end{array}$ & Cultures & $\begin{array}{c}\text { Carrier } \\
\text { rate }\end{array}$ & Cultures & $\underset{\text { rate }}{\text { Carrier }}$ \\
\hline $\begin{array}{l}1-3 \\
4-6 \\
7-9 \\
>9\end{array}$ & $\begin{array}{c}\text { No. } \\
76 \\
63 \\
53 \\
94\end{array}$ & $\begin{array}{c}\% \\
31.6 \\
27.0 \\
32.1 \\
52.1\end{array}$ & $\begin{array}{l}\text { No. } \\
25 \\
21 \\
16 \\
22\end{array}$ & $\begin{array}{c}\% \\
48.0 \\
57.1 \\
50.0 \\
63.6\end{array}$ & $\begin{array}{r}\text { No. } \\
59 \\
52 \\
36 \\
48\end{array}$ & $\begin{array}{c}\% \\
44.1 \\
19.2 \\
30.6 \\
18.8\end{array}$ & $\begin{array}{l}\text { No. } \\
295 \\
251 \\
245 \\
713\end{array}$ & $\begin{array}{c}\% \\
30.2 \\
26.7 \\
31.4 \\
45.3\end{array}$ \\
\hline Total & 286 & 37.2 & 84 & $54.8^{*}$ & 195 & 29.3 & 1,504 & 37.0 \\
\hline
\end{tabular}

* Patients treated with tetracycline had a higher carrier rate and patients treated with erythromycin a lower carrier rate than untreated patients $\left(\chi^{2}: \mathrm{p}<0.01\right)$. 


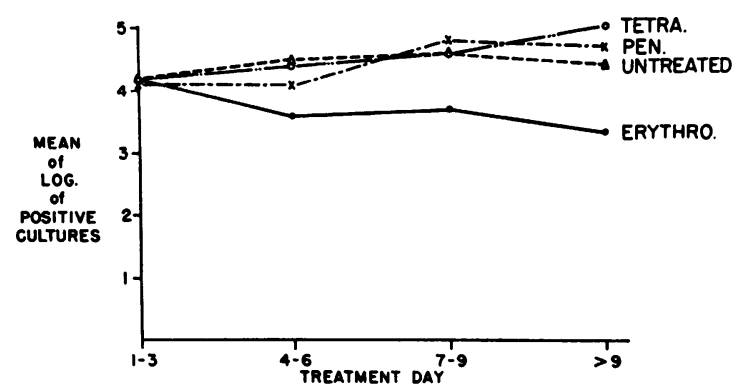

Fig. 3. Only tREatment With eRythromycin LoWERED THE MEAN NUMBER OF STAPHYLOCOCCI ISOLATED FROM CARRIERS; TREATMENT WITH PENICILLIN OR TETRACYCLINE DID NOT CHANGE THE NUMBER OF STAPHYLOCOCCI ISOLATED.

The number of staphylococci recovered from patients who remained carriers did not change during treatment with penicillin or tetracycline, as compared with untreated patients (Figure 3 ). During treatment with erythromycin there was a significant decrease in the number of staphylococci.

In addition to changes in carrier rates and in quantitative counts, treatment with all three drugs increased the proportion of staphylococci which were resistant to penicillin and tetracycline and lysed by either phages $80 / 81$ or by phages of group III (Figure 4).

Quantitative counts in untreated patients with various illnesses. The distribution of counts from 106 untreated patients with at least five consecu-

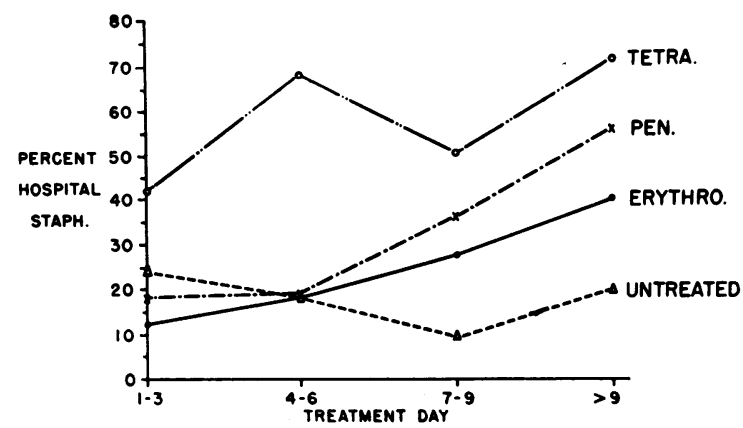

Fiti. 4. THE PROPORTION OF STAPHYLOCOCCI WHICH WERE RESISTANT TO BOTH PENICILLIN AND TETRACYLINE AND LYSED BY PHAGES $80 / 81$ OR PHAGES OF GROUP III INCREASED DURING TREATMENT WITH ALL THREE ANTIMICROBIAL DRUGS. No significant changes occurred in untreated patients.

tive cultures was not a bell-shaped curve but was skewed to counts greater than $10^{6}$. It was found that the positive cultures from patients with diaketes, patients with illnesses which terminated in death during hospitalization, and patients with staphylococcal infections contained more than $10^{4}$ colonies per swab more frequently than did positive cultures from untreated patients with other diseases (Table VI).

No significant differences could be detected in the distribution of counts from patients with other illnesses, but only a few patients with leukemias or disseminated carcinomas were studied.

In the 26 untreated patients with staphylococcal infections, nasal cultures were negative for

TABLE VI

Quantitative counts in untreated patients with different illnesses

\begin{tabular}{|c|c|c|c|c|}
\hline & Diabetics & Fatal illnesses & $\begin{array}{c}\text { Staph. } \\
\text { infections }\end{array}$ & $\begin{array}{l}\text { Other patients } \\
\text { (with more than } \\
5 \text { cultures) }\end{array}$ \\
\hline $\begin{array}{l}\text { No. of patients } \\
\text { No. of cultures } \\
\text { Carrier rates }\end{array}$ & $\begin{array}{l}21 \\
94 \\
45.7\end{array}$ & $\begin{array}{l}15 \\
65 \\
44.6\end{array}$ & $\begin{array}{l}26 \\
26 \\
84.6^{*}\end{array}$ & $\begin{array}{r}91 \\
1,020 \\
36.0\end{array}$ \\
\hline \multicolumn{5}{|c|}{ Quantitative counts of positive cultures } \\
\hline $\begin{array}{l}10^{1}-10^{2} \\
10^{2}-10^{3} \\
10^{3}-10^{4} \\
10^{4}-10^{5} \\
10^{5}-10^{6} \\
10^{6}-10^{7}\end{array}$ & $\left.\begin{array}{c}4.7 \\
34.9 \\
30.2 \\
30.2\end{array}\right\} 95.3^{*}$ & $\left.\begin{array}{l}27.6 \\
31.0 \\
41.4\end{array}\right\} 100.0^{*}$ & $\left.\begin{array}{r}22.7 \\
9.1 \\
68.2\end{array}\right\} 100.0^{*}$ & $\left.\begin{array}{l}2.2 \\
10.4 \\
21.5 \\
32.4 \\
15.8 \\
17.7\end{array}\right\} 65.9^{*}$ \\
\hline Total & 100.0 & 100.0 & 100.0 & 100.0 \\
\hline
\end{tabular}

* Patients with diabetes, fatal illnesses or staphylococcal infections had a larger proportion of positive cultures with more than $10^{4}$ colonies per swab $\left(\chi^{2}: p<0.1\right)$, and the carrier rate in patients with staphylococcal infections was higher than in all other untreated patients. 
staphylucocci in only 4 , and in all but 3 of the 22 patients with positive nasal cultures the staphylococci from the nose and the lesion were of the same phage type.

\section{DISCUSSION}

These studies have shown that a significantly higher proportion of hospital-acquired staphylococcal infections was due to phage type $80 / 81$ staphylococci than could be explained by the proportion of these staphylococci in the nose of hospitalized patients. In part, the predominance of this organism might be explained by the observation that staphylococci lysed by $80 / 81$ phages were more frequently multiple drug-resistant than were staphylococci of other phage groups. Most of the infections occurred in patients receiving antibiotics for other reasons, and drug-resistant strains would tend to be selected as the etiological agents. In this way, $80 / 81$ staphylococci would be more frequently selected than strains which were less frequently drug-resistant.

In addition, carriers of phage type 80/81 staphylococci tended to have larger numbers of staphylococci in the nose than had carriers of other staphylococci, in the absence of antimicrobial therapy. Gould (10) has demonstrated that considerable amounts of penicillin can be recovered from the noses of hospital patients who are not receiving systemic penicillin; aerial dissemination in areas of mixing and administration of the drug was thought to be responsible for this finding in his studies. By this means, it is possible that penicillin could depress the quantity of penicillinsusceptible strains that could be recovered and would provide an explanation for the increased numbers of staphylococci observed in carriers of $80 / 81$ strains which were usually penicillin-resistant. Since contamination of a patient's environment was more frequent in patients with higher counts, $80 / 81$ strains would tend to be more widely disseminated because of their increased quantity in carriers.

In several reports, an increased virulence of phage type $80 / 81$ staphylococci has been postulated to explain the frequency with which this strain can be isolated from hospital-acquired lesions $(11,12)$. Elek and Conen (13) have reported that this strain does not produce lesions more frequently than other strains when injected into human volunteers in equal numbers; therefore, by this criterion, no evidence of increased virulence could be assigned to type 80 staphylococci. Although there may be significant differences in the capacity of various strains of staphylococci to initiate infections which would not be manifest in such experiments, no direct evidence for an increased virulence of $80 / 81$ staphylococci in man is available.

If virulence is not a factor, the reports that carriers of this strain have a higher incidence of infection than have other nasal carriers when they are removed from the hospital environment (11, 12) suggest that even in the absence of intensive antimicrobial therapy, larger numbers of staphylococci are available from the nose of carriers of $80 / 81$ staphylococci than from other carriers. No comparisons have been reported of the number of staphylococci of different phage types than can be recovered from individuals outside of hospitals, but some consideration should be given to the number of bacteria to which an individual is exposed in order to evaluate the virulence of a particular strain.

Although this report is concerned primarily with the relationship between nasal carriers and staphylococcal infections, it is probable that infected cases serve as major sources of further dissemination of staphylococci, once established. In the series reported by Williams and co-workers (1) the incidence of infections in patients who were not nasal carriers was 2 per cent, but 15 per cent of patients who were nasal carriers of tetracycline-resistant strains became infected. The increased incidence of infections was due to staphylococci of the same phage type as those present in the patient's nose before the infection appeared. If these figures are generally true, the staphylococci present in the patient's nose represent a greater direct hazard to the patient than do the staphylococci from lesions of other patients. Furthermore, the argument that a particular strain predominates in hospital infections because the infected case is a major source of infection, and this source was infected with this particular strain, does not satisfactorily explain why a few strains of the many different ones available from carriers should be a major cause of disease throughout the country (14).

Several studies have shown that patients may 
he intermittent or relatively constant nasal carriers of coagulase-positive staphylococci $(15,16)$. As shown in these studies, patients with high carrier rates also have a larger number of staphylococci in positive cultures than have patients with lower carrier rates. At the present time there is insufficient evidence to indicate that only consistent carriers are important in staphylococcal infections, but with additional data it may be possible to limit programs, designed to control staphyloccal infections through control of carriers, to consistent carriers of large numbers of staphylococci.

The effect of antimicrobial drugs on carrier rates and quantitative counts seemed to be related to the availability of drug-resistant staphylococci. Thus, tetracycline and penicillin to which 45 and 66 per cent of the strains were resistant, did not decrease either the carrier rates or the quantitative counts in patients who remained carriers. Erythromycin, to which only 21 per cent of the strains was resistant, reduced both carrier rates and quantitative counts in carriers. The changes observed during erythromycin treatment in this study were less marked than those observed in a mental hospital where no strains were resistant to erythromycin (7).

All three antimicrobial drugs increased the proportion of staphylococci which were multiple drugresistant and lysed by phages of group III or phages $80 / 81$. Staphylococci with these characteristics are responsible for a large majority of hospital-acquired infections throughout the country (14) and, as shown in these and other studies, antimicrobial therapy is responsible for maintaining a large reservoir of these organisms in nasal carriers within hospitals.

The possible explanation for the higher carrier rates and higher quantitative counts in patients with diabetes, staphylococcal infections and fatal illnesses is even more complex. Three of the 22 carriers with staphylococcal infections were observed to have nasal counts of greater than one million colonies per swab for two to three months before the appearance of staphylococcal skin infections. In each instance, the staphylococci from the nose and from the lesions were of the same phage type. No cultures were taken from the remaining patients until staphylococcal infections were present and, therefore, it was not possible to determine whether high nasal counts preceded or followed staphylococcal infections. Since large numbers of organisms were present in the nose, they constituted a reservoir from which staphylococci could be disseminated, in addition to the obvious hazards of an open lesion.

Patients with diabetes or debilitating diseases also have a higher incidence of staphylococcal infections (17). The large numbers of nasal staphylococci in patients with these diseases may be a reflection of a generalized increased susceptibility to infections due to unknown causes.

Regardless of the explanations, the presence of large numbers of nasal staphylococci in patients may be important in the dissemination of staphylococci to the hospital environment and in the etiology of the patient's own hospital-acquired staphylococcal infection.

\section{SUMMARY}

A larger proportion of hospital-acquired staphylococcal infections was due to phage type $80 / 81$ staphylococci than could be explained by the prevalence of these staphylococci in the noses of hospitalized patients. In part, these observations may be explained by the findings that staphylococci lysed by $80 / 81$ phages were more frequently multiple drug-resistant than other staphylococci and were present in larger numbers in uninfected, untreated nasal carriers than were other strains.

Sweep plates of patients' clothing were more frequently positive for coagulase-positive staphylococci in patients with nasal counts greater than 10,000 colonies per swab than in patients with counts below 10,000 .

Higher nasal quantitative counts of positive cultures were observed in untreated patients with high carrier rates and in patients with diabetes, staphylococcal infections or fatal illnesses.

The predominant effect of antimicrobial drugs on the carrier status was to select multiple-resistant strains. The effects of drugs on carrier rates and quantitative counts were related to the availability of staphylococci resistant to the administered drug.

\section{REFERENCES}

1. Williams, R. E. O., Jevons, M. P., Shooter, R. A., Hunter, C. J. W., Girling, J. A., Griffiths, J. D., and Taylor, G. W. Nasal staphylococci and sepsis in hospital patients. Brit. med. J. 1959, 2, 658. 
2. Weinstein, H. J. The relation between the nasalstaphylococcal-carrier state and the incidence of postoperative complications. New Engl. J. Med. 1959, 260, 1303.

3. Knight, V., and Holzer, A. R. Studies on staphylococci from hospital patients. 1. Predominance of strains of Group III phage patterns which are resistant to multiple antibiotics. J. clin. Invest. 1954, 33, 1190.

4. Knight, V., and White, A. Drug-resistant staphylococci: Part I. Their distribution in hospital patients. Sth. med. J. (Bgham, Ala.) 1956, 49, 1173.

5. Clarke, S. K. R. Nasal carriage of Staphylococcus aureus. J. Path. Bact. 1957, 73, 253.

6. Rountree, P. M., Freeman, B. M., and Barbour, R. G. Nasal carriage of Staphylococcus aureus in the general population and its relationship to hospitalization and penicillin therapy. Med. J. Aust. 1954, $2,457$.

7. White, A., Hemmerly, T., Martin, M. P., and Knight, V. Studies on the origin of drug-resistant staphylococci in a mental hospital. Amer. J. Med. 1959, $27,26$.

8. Knight, V., White, A. C., and Martin, M. P. The effect of antimicrobial drugs on the staphylococcal flora of hospital patients. Ann. intern. Med. 1958, 49, 536.

9. White, A. C., Foster, F., and Knight, V. Propagation of staphylococal phages in liquid medium. Antibiot. and Chemother. 1959, 9, 81.

10. Gould, J. C. Environmental penicillin and penicillin-resistant staphylococcus aureus. Lancet 1958, 1. 489.
11. Fekety, F. R., Buchlinder, L., Shaffer, E. L., Goldberg, S., Price, H. P., and Pyle, L. A. Control of an outbreak of staphylococcal infections among mothers and infants in a suburban hospital. Amer. J. publ. Hlth 1958, 48, 298.

12. Wentworth, F. H., Miller, A. L., and Wentworth, B. B. Observations relative to the nature and control of epidemic staphylococcal disease. Amer. J. publ. Hith 1958, 48, 287.

13. Elek, S. D., and Conen, P. E. The virulence of Staphylococcus pyogcnes for man. A study of the problems of wound infection. Brit. J. exp. Path. 1957, 38, 573.

14. Blair, J. E. Laboratory aspects of the problem of hospital-acquired staphylococcal disease in Proc. of Natl. Conf. on Hospital-Acquired Staphylococcal Disease, U. S. Dept. of Health, Education and Welfare, Communicable Disease Center. Atlanta, Ga., 1958, p. 112.

15. Knight, V., White, A., Foster, F., and Wenzel, T. Studies on staphylococci from hospital patients. II. Effect of antimicrobial therapy and hospitalization on carrier rates. Ann. N. Y. Acad. Sci. 1956, 65, 206.

16. Miles, A. A., Williams, R. E. O., and Clayton-Cooper, B. The carriage of Staphylococcus (pyogenes) aureus in man and its relation to wound infection. J. Path. Bact. 1944, 56, 513.

17. Rogers, D. E. Observations on the nature of staphylococcal infections. Bull. N. Y. Acad. Med. 1959, $35,25$. 